\title{
Development of an individual assessment instrument for critical care nursing students
}

\author{
Lena Stevens, Janet Yvonne Mattsson* \\ Department of Health and Technology Development, Red Cross University College, Stockholm, Sweden
}

Received: May 30, 2016

DOI: $10.5430 /$ jnep.v7n2p54
Accepted: September 12, 2016 Online Published: September 22, 2016

URL: http://dx.doi.org/10.5430/jnep.v7n2p54

\begin{abstract}
Critical care nurses need to possess theoretical knowledge, advanced skills as well as competencies and capabilities to care for critically ill patients in the challenging and fast changing environment of intensive care. In order to assess performance and learning in critical care nursing students in the clinical setting, a structured process enabling college faculty, clinical educators and students to work towards the same goals and learning outcomes is of outmost importance. In this study action research was used to develop an assessment instrument in a collaborative effort between faculty, clinical educators and students. The instrument was developed and tested at several clinical sites during a period of 11/2 years. Interviews were conducted with expert focus groups and students about the ease and feasibility of the instrument. Four themes emerged during the analysis of the interviews: clarity, helping me, arranging and timeliness. The analysis further revealed positive opinions about the structure, content and usability of the instrument. We conclude that the instrument helps in both assessing student performance and in revealing knowledge-gaps for the students in the critical care nursing program.
\end{abstract}

Key Words: Clinical learning, Clinical assessment, Critical care

\section{INTRODUCTION}

The World Health Organization ${ }^{[1]}$ has stated that "stronger emphasis should be placed on translating knowledge into action to improve public health by bridging the gap of what is known and what is actually done" ${ }^{[1]}$ Reports also show that $30 \%$ to $40 \%$ of all patients do not receive health care based on current relevant knowledge, and as many as $20 \%$ to $25 \%$ of all patients receive direct harmful or unnecessary care. ${ }^{[2]}$ These statements high-lights the needs of a rigorous and evidence-based clinical assessment process which connects theory with practice and supports transition of knowledge from one context to another in order to ensure health care professionals, including critical care nursing students, upon graduation have reached a satisfactory level of proficiency and possess the competencies necessary to function as independent practitioners.

\subsection{Critical care education in Sweden}

The preparation to become a critical care registered nurse in Sweden involves post-graduate studies, where in most institutions, the student receives both a professional degree (critical care specialty nurse) and an academic degree (one-year masters' degree in nursing). Subsequently the programs build both on theoretical as well as practical learning opportunities. Programs offered can involve full-time studies or part-time studies depending on the school and the choice of the student. Completion of the program renders a total of 60 credits out of which 15 credits is comprised of a masters' thesis within

\footnotetext{
${ }^{*}$ Correspondence: Janet Yvonne Mattsson; Email: janet.mattsson@ rkh.se; Address: Red Cross University College, Teknikringen, Stockholm, Sweden.
} 
the subject critical care nursing. All programs, as mentioned above, include theoretical education integrated with clinical rotations. The combination of theoretical learning and clinical learning provides a specific opportunity for enhanced learning and renders the students possibilities to apply their new knowledge in its natural socio-cultural context.

In Sweden, faculty is not present on-site during the clinical rotations due to legal restrictions and are not able to directly observe and evaluate the transition of knowledge during the students' clinical rotation. During the clinical rotations students are instead followed by a clinical educator and a personal preceptor, both employed by the hospital close collaboration and clear communication between faculty and clinical educators is in other words of outmost importance to ensure high quality student learning.

The concept of learning in this study is viewed as proposed by Illeris ${ }^{[3]}$ as being constructivist in nature, which can be understood as learning taking place in a collaboration between one self, others and the surrounding context. In this way the learning can be viewed as constructed in dynamic interaction with the physical as well as the social learning environment. Learning is, as highlighted by Stalhem-Smith ${ }^{[4]}$ and Schunk ${ }^{[5]}$ not something objective that is only transmitted from teacher to student. This is an important aspect to consider when designing learning opportunities and learning outcomes for students in practical as well as theoretical education. As described by Illeris, ${ }^{[3]}$ several conditions are involved in learning and will actively influence the students' learning process. For instance, the students' learning is dependent on the application of his or hers own external and internal conditions. From these influences the learner actively builds, or constructs, learning as mental structures. ${ }^{[6]}$ These mental structures will help them to obtain the competencies required to function as independent practitioners.

\subsection{Competency in the critical care field}

Competence is a complex concept and there are a number of definitions available. Illeris ${ }^{[7]}$ argues that the concept of competence often is broad and open as well as weekly defined. Epstein and Hundert ${ }^{[8]}$ propose a broad definition viewing competence as "the habitual and judicious use of communication, knowledge, technical skills, clinical reasoning, emotions, values and reflection in daily practice for the benefit of the individual and community being served". Cowan, Norman and Coopamah ${ }^{[9]}$ argue for a holistic definition of competence for the nursing profession as a combination of knowledge, performance, skills and attitude required for becoming successful. Miller, Hoggan and Pringle ${ }^{[10]}$ on the other hand suggested competence to be divided into two different significances: the first is competence as performance, e.g., how well we perform and function, and the second is competence as a psychological construct which refers to the ability to integrate cognitive, affective and psychomotor skills. The Canadian Nurses' Association integrate both these latter aspects when defining competency as "the ongoing ability of a nurse to integrate and apply knowledge, skills, judgement and personal attributes required to practice safely and ethically in a designed role or setting". [11] This definition implies a constant dynamic environment where the nurse needs to interpret and adapt to unique situations. Roberts $^{[12]}$ even compares assessment of nursing practice to assessment of performing arts, as it is fluid, never the same twice and requiring the nurse to adapt to the specific patients' changing and unique situation. Describing a similar view, Fraser and Greenhalgh ${ }^{[13]}$ add the concept capability as an extension of competency when they define competency as "what individuals know or are able to do in terms of knowledge, skills and attitude" and capability as "the extent to which individuals can adapt to change, generate new knowledge and continue to improve performance." Using Fraser and Greenhalg's definition as point of departure, it appears the critical care student-nurse should possess both competencies and capabilities as well as the ability to transfer knowledge between contexts in order to be successful in the ever-changing environment of critical care.

Competencies for critical care nurses as described by the European Federation of Critical Care Nursing Associations (EfCCNa) ${ }^{[14]}$ and the Swedish Association for Critical Care and Anesthesia Nurses (AnIva), ${ }^{[15]}$ is a reflection of an acceptable level of knowledge and clinical skills the entry-level critical care nurse is expected to possess in order to deliver safe and high-quality care to the critical care patient. In addition to these specific competencies for critical care nurses, the Higher Education Ordinance in Sweden ${ }^{[16]}$ has developed requirements and goals for post-graduate specialty nursing programs in general, which also need to be met for successful graduation. Despite the differences in the definitions of competence it appears assessment of many of the competencies and capabilities we strive for can only be carried out and assessed in the real setting, and subsequently a thorough and structured assessment with ensuing feed-back on performance during clinical rotations, becomes a very important factor for outcome and the for students' learning.

\subsection{Assessment of competence and capability}

The aim of the critical care nursing program is to facilitate the students development of professional competence, which comprises the abilities and capabilities of the person in relation to situation and context in practice. ${ }^{[17]}$ All critical care nursing programs in Sweden integrate theoretical didactic 
education with clinical rotations. The final grade received for each course reflects a summary of grades on all written and verbal exams, as well as the grade based on the assessment of performance during the clinical rotation.

The clinical rotation grade requires, in other words, just as a secure and fair evaluation-process as the theoretical evaluations and exams.

Zasadny and Bull ${ }^{[18]}$ describe the assessment of competence as an interpretive act at the same time as they state the importance of accurate assessment. Although learning objectives are stated in the syllabus, clinical educators, preceptors and students all bring different prior experiences and personalities along, which can cause confusion and discrepancies when interpreting the learning objectives. However, it is imperative that all involved are clear about goals and expectations and work together to reach a fair assessment. The preceptors' approach to the student can be viewed as key in enabling the student's ability to integrate and apply theoretical knowledge into the practice setting while working towards the goals. The preceptors' role is of outmost importantance, since they are in a position to enhance or hinder learning to in the clinical rotation. ${ }^{[19]}$

In order to facilitate interpretation of the learning objectives; to clarify expected outcomes and related criteria; to strengthen the quality of the clinical assessment-process and to guide the preceptors' understanding of the outcomes, Kapborg \& Berertö, ${ }^{[20]}$ suggest that an instrument or a tool is used. The document or form used should also, according to Epstein and Humbert ${ }^{[8]}$ "provide guidance and support to address learning needs".

The aim of this study was to develop and evaluate a new individualized instrument that helps to uncover individual knowledge-gaps at the same time as it reflects the general learning objectives, competencies and capabilities for critical care nursing. The instrument also needs to serve as a reliable guide when determining final grades for the course.

\section{METHOD}

This study is based on the constructivistisc assumption that findings are co-created by researchers and participants in the study and that the sociocultural perspective, meaning knowledge, is seen as a creation in interaction with the subjects and the context. This research, which involves both the researchers and the participants in close collaboration, is a central feature in action research. ${ }^{[21]}$ Using this research strategy, we aimed to disclose the gap between the real and ideal as well as develop a new assessment instrument within the specialist nursing education.
Permission to conduct the study was requested and granted by the program director of the critical care nursing program where the students were enrolled and by the nurse managers at the critical care wards were the clinical educational leaders and the preceptors worked. According to Swedish law and the Act on Ethical Review of Research Involving Humans ${ }^{[22]}$ and the Personal Data Act ${ }^{[23]}$ an ethical review was not needed, as the informants were all over18 years of age and able to accept or decline participation in the study. Informed consent was obtained from all informants after they had received information about the study both verbally and in writing. The informants were informed that participation was voluntary and that they at any time could terminate participation in the study without further questions being asked.

\subsection{Design}

The design of this study builds on the cyclical process of action research described by Susman and Evered. ${ }^{[24]}$ It is a five step process that encompasses diagnosing, action planning, action taking, evaluating and specifying learning. Additionally, the authors added a sixth step, a final evaluation one year after the implementation of the new instrument. This design establishes validity, which is essential within a high quality learning environment which recognises and supports good teaching.

Prior to moving into the diagnostic phase, a client-system interface was established. This meant establishing interaction between college faculty, and the clinical educators. This approach is described by O'Brien ${ }^{[25]}$ and involves meetings and introductions with key persons involved in the project. For the authors this was of particular interest since a change in the curriculum at the Red Cross University College critical care program had recently occurred and needed to be communicated. This change aimed to strengthen the studentcentered learning (SCL) and self-directed learning (SDL), and required clarification of the learning objectives. The changes also reflected a move towards supporting the students to uncover their own learning needs in relation to learning outcomes. This change called for an improved assessment process and a new assessment instrument for the clinical rotations in the critical care program. The instrument needed to reflect competencies and learning objectives as well as progression of learning throughout the program.

The change made also reflected the aims of the Bologna process as it requires faculty to equip students with the knowledge, skills and transferable competencies they need to succeed after graduation. The Bologna process is a collective effort of public authorities, universities, teachers, and students, together with international organizations, including

ISSN 1925-4040 E-ISSN 1925-4059 
the European Commission, to strengthen quality assurance through higher education in the European Union.

In the first step diagnosing, we aimed to uncover the gap between the "ideal and the real". This can be accomplished in various ways and the choice of data collection is dependent on the feasibility of the method as well as consideration of access to the field of interest. In this study two of the faculty members from the critical care program met with three, clinical educational leaders, with extensive background in critical care nursing and several years' experience as clinical educators. This expert group strengthens the content validity as they were all familiar with the critical care program and the learning objectives for all courses and they brought specific experience from the clinical setting and its demands. The discussions with the expert focus group revolved around content, feasibility of use and lay-out of the instrument. After two conducted focus group interviews it became clear, through analysis of the discussions, that the new instrument would serve as a formative and summative assessment, and it would also form as a base for developing a plan for further learning. The instrument needed to clearly uncover any knowledge-gaps the specific student might have and serve as a reliable guide when determining final grades for the course.

The assessment process and the instrument used in the past required completion at two times during the students' clinical rotation; at half-time of the rotation and at the completion. The authors felt this was a concept well in accordance with using both formative and summative evaluation and as it had worked to everyone's satisfaction in the past we decided to continue with the two-step process of clinical assessment.

In the second step, action planning, a search for instruments currently used, specifically in critical care specialty nursing programs, both nationally and internationally, was conducted. This yielded the SPECT instrument developed by Gill et al. in Australia. ${ }^{[26]}$ SPECT uses domains of knowledge and skill competencies reflecting many of the competencies described by EfCCNa and AnIva. Another strength of the SPECT instrument is its comprehensive content reflecting components such as socio-emotional and communication skills developed on the basis of interviews with healthcare consumers. ${ }^{[27]}$ The importance of communication skills with patients and families, echoed the findings of the CoBaTrICE collaboration. ${ }^{[28]}$ Face and content validity was also tested of the SPECT instrument. The domains were revised to fit the learning objectives and the requirements of the Swedish system and specific socio-cultural context.

A pilot of an assessment instrument based on the requirements and objectives described above was developed. Collaboration with the expert focus group played a significant role in this development especially as the group represented different critical care units covering different ages and critical care specialties. The expert group was invited to evaluate and discuss the developed pilot and revisions were made according to their suggestions.

Since the critical care program at the Red Cross University College is divided in to two clinical courses. The assessment instrument needed to make a progression of knowledge and skills visible. Blooms taxonomy was used to distinguish clinical rotation 1 and clinical rotation 2 although domains and competencies remained the same. For example, the competency pertaining to evaluation of blood-gases and other laboratory data reads for clinical rotation $1: \ldots$ with support from the preceptor discusses blood-gas results... The same competency for clinical rotation 2 reads... Independently analyzes blood-gas results...

During the third step, action taking, the instrument was trialed at four different critical care units during seven students' first clinical rotation. The units that were chosen included both specialty critical care units (i.e., pediatric and neurosurgery) as well as two regular ICUs where both surgical and medical adult critical care patients were cared for. In order to facilitate use of the instrument and to evaluate preceptors' and students' responses in using the new instrument faculty was present during the half-time meetings. Faculty presence also served to strengthen the outcome and relationship validity of the instrument.

This led in to the fourth step, evaluation. Preceptors and students were asked semi-structured, open-ended questions relating to how easy the instrument was to understand and its' clinical feasibility and content. Their replies were documented by the authors and presented at the next expert focus group meeting with the clinical educators. After discussions and analysis additional revisions were made. This revision resulted in a final version of the instrument which was presented at a meeting attended by all faculty, nurse-managers and clinical educators involved with the program.

During the next step, specifying learning in the clinical rotation, all students $(n=18)$, and preceptors within the critical care course used the instrument. To ensure process validity the students received instructions on how to use the instrument before leaving the college for their clinical rotation, and the clinical educators instructed all preceptors on the use of the instrument. Faculty were again present at the half-time meetings. As in the previous semester, open-ended semistructured questions were used pertaining to the instruments' face validity and clinical feasibility. Some minor revisions were made as a conclusion of the views and opinions relayed by students, preceptors and the expert-group. For example: 
The wording of the competency item reflecting teaching in the clinical setting was broadened to encompass not only patients but next of kin and/or co-workers. On the final page of the instrument a line was also added where the student and the preceptor, after the midterm discussion, clarify the goals to work towards during the remainder of the clinical rotation. A plan on how to achieve these goals is also agreed upon and documented here.

As a final evaluation and a sixth step in the action research process, an evaluation one year after the implementation of the new instrument was conducted. This evaluation added interrater reliability to the instrument (see Table 1) as it penetrated the consistency in judgment both by the students and the preceptors, as well as their consensus of what the instrument measured and how. The three clinical educators who had formed the expert focus group and had provided feed-back throughout the development and implementation of the instrument, were gathered for a group-interview. The questions asked were: What are your thoughts after using the new instrument as an assessment tool? Was the instrument helpful in identifying the students' knowledge gaps? Was the instrument helpful in identifying a plan to fill those knowledge gaps and reaching the goals? Did the instrument reflect a reasonable knowledge and performance level?

During this step a new group of students $(\mathrm{n}=13)$, was introduced to the new instrument (see Table 1) and used it during their clinical rotation. These students were also interviewed in smaller groups about their experiences of using the instrument. The following questions were asked: -What are your thoughts after using the new instrument as a learning tool? -Was the instrument helpful in identifying your knowledge gaps? -Was the instrument helpful in supporting ways to fill those knowledge gaps and reach the goals? -Was the instrument useful in identifying a reasonable knowledge and performance level for your clinical rotation?

Table 1. View of ndividual assesment instrument

\begin{tabular}{|c|c|c|c|c|c|c|}
\hline \multicolumn{7}{|c|}{ Assessment, monitoring and evaluation of patient data; documentation and reporting } \\
\hline \multicolumn{7}{|c|}{$\begin{array}{l}\text { Corresponding course objectives } \\
\text { - Assess, analyzes and explains pathophysiological changes in the critically ill patient } \\
\text { - Demonstrates the ability to formulate and document a patient centered plan of care } \\
\text { - Independently assesses and evaluates nursing interventions for the critical care patient based on research and evidence }\end{array}$} \\
\hline & \multicolumn{3}{|c|}{$\begin{array}{l}\text { Midterm assessment } \\
\text { Date_ }\end{array}$} & \multicolumn{3}{|c|}{$\begin{array}{l}\text { Final assessment } \\
\text { Date }\end{array}$} \\
\hline & $\begin{array}{l}\text { Satisfactory } \\
\text { progress }\end{array}$ & $\begin{array}{l}\text { Not satisfactory } \\
\text { progress }\end{array}$ & Comments & Achieved & Not achieved & Comments \\
\hline \multicolumn{7}{|l|}{$\begin{array}{l}\text { Independently analyzes and } \\
\text { evaluates patient data from physical } \\
\text { assessment and monitors }\end{array}$} \\
\hline \multicolumn{7}{|l|}{$\begin{array}{l}\text { Independently analyzes and } \\
\text { prioritizes nursing interventions } \\
\text { according to current patient status }\end{array}$} \\
\hline \multicolumn{7}{|l|}{$\begin{array}{l}\text { Reports findings in a systematic and } \\
\text { structured way }\end{array}$} \\
\hline $\begin{array}{l}\text { Documents concisely and according } \\
\text { to hospital guidelines }\end{array}$ & & & & & & \\
\hline
\end{tabular}

All the focus group interviews were taped, transcribed verbatim and then analyzed thematically together as a whole. This analysis did not lead to any new changes of the instrument.

\section{RESUlts}

During the final analysis where the collected data from the expert focus-group and from the four student groups was analyzed, the following themes emerged: Clarity, Helping me, Arranging and Timeliness.

\subsection{Clarity}

After having trialed the instrument both preceptors and the student groups expressed satisfaction with the ease of use of the instrument. They felt the domains and competencies were easy to understand and also expressed they felt the domains clearly reflected course objectives and current clinical practice. The following excerpts highlights this theme:

"Using it helped our preceptors to understand the learning goals the school have for the clinical rotation."

Both groups also expressed a consensus regarding the mean- 
ing of the words used to clarify learning goals in the instrument.

Furthermore, the groups conveyed a cohesive opinion that all essential context of a critical care nurse's practice (assessment and management of critically ill patients, communication, patient safety, team work and ethical considerations) was evident in the instrument;

\subsection{Helping me}

This theme conveyed how the instrument was helpful in identifying knowledge gaps and prioritizing learning needs as well as helping the students when formulating their thoughts on how they would like their preceptor to support their learning. The following excerpts highlights this theme:

"When we talked about policies and guidelines the instrument clearly helped in finding and defining this specific students' knowledge gaps."

"The structure helped to define the knowledge-gaps and then summarize them at the end and guided us when forming a plan for how to fill those gaps."

\subsection{Arranging}

The expert-group and the student groups as well as the preceptors expressed a positive view of the lay-out of the instrument. The expert-group felt it reflected both a formative and a summative assessment where progression towards proficiency, or lack thereof, was clearly visible. The student group conveyed a visible strong emphasis on being responsible for and owning their own knowledge development when actively using the instrument during the clinical rotation. The preceptors conveyed a feeling of relief as they found the instrument helpful in continuously motivating and challenging the student to learn even though the student had reached the learning goals. The previous assessment-instrument used a Likert scale to depict progression and this became, according to the clinical educators, often biased and interpreted differently by different preceptors. The following excerpts highlights this theme:

"The instruments give everyone a minimum level to aspire to- it sets the bar at the same time as it reflects our national competencies for critical care nurses."

"The students are clearly motivated to see what else they need to learn. For example, this one student who was very proficient; after the half-time meeting we were able to identify other areas where he could be challenged and where he could continue to grow."

\subsection{Timeliness}

In this theme the time frame emerged. The instrument was viewed as helpful for the preceptors and students when keep- ing track of the time they had together at their disposal during the clinical rotation. The instrument also helped them and to prioritize learning goals. The instrument became a time saver as it was easy to understand. This was of particular value to the students and the preceptors as there often is limited time during the clinical rotation to sit down and discuss learning goals in a structured way. The following excerpts highlights this:

"Even when more than one preceptor was involved, it seemed the instrument helped to keep assessments uniform."

"The time allotted was perfect. Having a limited time for the discussion helps everyone to prioritize."

\section{Discussion}

The learning process during clinical rotations for critical care nursing students need guidance as well as opportunity for reflection together with experienced mentors. The situation at our program-location do not allow faculty access to the clinical setting and the assessment of knowledge-transfer and progression towards stated learning outcomes, is instead supervised by clinical educators and preceptors. It is therefore of outmost importance all involved have a coherent view of competencies and learning-outcomes. This coherence was explicit in the interviews with the expert-group, with the preceptors and with the students. It became evident that with the aid of a clear process and instrument, they all felt they now have a common language and shared understanding and interpretation of the domains and competencies. With that in mind it is our expectation that the assessments can now be carried out independently, without faculty presence, with the help of the instrument.

There is, however, always possibilities for personal interpretations which can impact assessment and discussions.

The dependent relationship of the students to the program and to preceptors and faculty needs to be taken into consideration. The students' positive opinions could reflect a desire for agreement in order to obtain a favorable assessment and a passing grade.

This study was carried out with 18 students at a smaller college in one geographical location. Although $\mathrm{EfCCNa}^{[14]}$ and AnIva ${ }^{[15]}$ competencies have been developed for the European, and AnIVA especially for the Swedish, critical care nurse, other programs might use the competencies differently and formulate competencies according to their specific learning objectives. Subsequently the results from this particular study can only be applied in the setting where it was performed.

According to the instructions for using the instrument two 
separate documents should be completed prior to the meeting. One document is completed by the student and the other by the preceptor. The two documents are then compared and discussed during the meeting. This process reflects the pedagogical view of the program, self-directed learning, as it engages the students and promotes their involvement and responsibility for their own learning. Deeper discussions between students and preceptor are also encouraged when two separate documents are compared and discussed. The instrument document was, however, in some instances completed by the student and the preceptor together during the meeting. This could lead to a cohesiveness and agreement between student and preceptor of views that not necessarily was the fact from the beginning.

In our study faculty was present at the meetings with students and preceptors. This was due to the instrument being new and never previously used but also to explain and answer any questions that would arise. The presence of faculty could impact answers and the results of this study. Faculty presence is not planned for the future and students and preceptors will use this instrument on their own during the students' clinical rotations. This change can have an impact on the use of the document and the assessment process as a whole, if misinterpretations or disagreements on content occur. An additional evaluation of the document should be carried out after its' use without faculty presence to evaluate if further specifications and clarification of the competencies and language are needed.

It would further be of interest to test and evaluate the instrument in other critical-care clinical settings connected to other college-programs. This would enable testing of the competencies and domains where the programs specific learning objectives and the specific socio-cultural variations would be reflected.

\section{Clinical implication}

The critical care clinical arena is becoming increasingly complex. It is of outmost importance to educate nurses caring for the most critically ill patients to practice, not only safely, but with a solid and deep understanding of all processes and behaviors that will surround them. During critical care nursing students' clinical rotations transfer of knowledge from theory to clinical practice is expected. For this to occur the student will need support from faculty as well as from clinical educators and preceptors. The need for a comprehensive and structured, yet clinically feasible assessment, is vital to support critical care nursing students on their journey towards professional competency. An assessment instrument can play a vital role in this process and help to develop a safe and knowledgeable practitioner. The instrument can guide preceptors and students through different domains and competencies specific for critical care, as well as assist them in finding the students' individual knowledge-gaps and encourage discussions between preceptor and student on how to overcome these gaps.

The guided discussions and reflections between preceptor and students which support the student in his or her selfassessment, is key in self-directed learning. The skills of self-directed learning are furthermore an asset for the student in their future professional role. In our high-tech society information and knowledge-sharing happens fast and individuals need to take personal responsibility for keeping abreast of new developments and having a structured and efficient way of bridging knowledge-gaps.

Finally, the instrument could serve as a guide in developing a clinical final examination for critical care nursing students. The domains and the competencies in the above described instruments reflect much of what can be expected knowledge and skill level for the graduating student. The question of a final clinical examination is discussed by many schools and also by the Swedish Association of Anesthesia and Critical care nurses, AnIVA. ${ }^{[15]}$ The advantages of a final clinical examination are many, and if used as a national standard would help to benchmark the knowledge and skill level of an entry-level critical care nurse. We suggest this instrument could form a base for a development of a final clinical exam.

\section{ACKNOWLEDGements}

The authors wish to thank Fenella J. Gill, Gavin D. Leslie, Carol Grech, Duncan Boldy and Jos M. Latour who developed the SPECT instrument and graciously let us use their instrument as a base for the development of ours.

\section{CONFlicts OF INTEREST Disclosure}

The authors declare that there is no conflict of interest.

\section{REFERENCES}

[1] World Health Organization. World Report on Knowledge for Better Health. 2004. Available from: http://www. who.int/rpc/meet ings/wr2004/en/index 2 .html
[2] Grol R, Grimshaw J. From best evidence to best practice: effective implementation of change in patients' care. Lancet. 2003; 362(9391): 1225-30. http://dx.doi.org/10.1016/S0140-673 $6(03) 14546-1$ 
[3] Illeris K. Contemporary theories of learning theorists-In their own words. Illeris K, editor. Oxon: Routledge; 2009.

[4] Focusing on active, meaningful learning: Hearing before the IDEA paper No 34. 1988.

[5] Schunk D. Learning Theories: an educational perspective Boston: Pierson; 2012.

[6] Illeris K. Towards a contemporary and comprehensive theory of learning. International Journal of Lifelong Education. 2003; 22(4): 396-406. http://dx.doi .org/10.1080/02601370304837

[7] Illeris K. Kompetens: [vad, varför, hur]. Competence (what, why, how). Lund: Studentlitteratur; 2013.

[8] Epstein RM. Hundert EM. Defining and Assessing Professional Competence. JAMA. 2002; 287(2): 226-235. http://dx.doi .org/10. $1001 /$ jama. 287.2.226

[9] Cowan DT, Norman I, Coopamah VP. Competence in nursing practice: A controversial concept-A focused review of literature. Accid Emerg Nurs. 2007; 15(1): 20-6. PMid:17276294 http://dx.doi . org $/ 10.1016 / j$. aaen .2006 .11 .002

[10] Miller C, Hoggan J, Pringle S, et al. Credit where credit's due. in: Report of the Accreditation of Work-based Learning Project. Scottish Vocational Education Council (SCOTVEC). Glascow: 1993.

[11] Canadian Nursing Association. Position statement. 2015. Available from: https://www.cna-aiic.ca/ /media/cna/page-conte

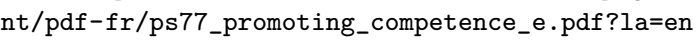

[12] Roberts D. Grading the performance of clinical skills: Lessons to be learned from the performing arts. Nurse Education Today. 2011; 31: 607-610. PMid:21074300 http://dx.doi.org/10.1016/j .ned t. 2010.10.017

[13] Fraser SW, Greenhalgh T. Coping with complexity: educating for capability. BMJ. 2001; 323(7316): 799-803. PMid:11588088 http://dx.doi.org/10.1136/bmj .323.7316.799

[14] European Federation of Critical Care Nursing Associations. EfC$\mathrm{CNa}$ Competencies for European Critical Care Nurses. 2013. Available from: http://www.efccna.org/images/stories/publ ication/competencies_cc.pdf

[15] AnIva. Kompetensbeskrivning (Description of Competencies) Riksföreningen för Anestesi \& Intensivvård and SSF, Sweden. 2014. Available from: http://www.aniva.se/wp-content/uploads /2014/12/kompetensbeskrivning_intensivvard.pdf

[16] SFS. Higher Education Ordinance in Sweden, Ministry of Education. 1993. Available from: http://www.riksdagen.se/sv/dokume nt-lagar/dokument/svensk-forfattningssamling/hogsk oleforordning-1993100_sfs-1993-100/

[17] Camelo S, Henriques H, Angerami E, et al. Professional Competence: The building of concepts and strategies developed by health services and implications for nursing. Text Context Nursing. 2013; 22(2): 552-60. http://dx.doi.org/10.1590/S0104-0707201 3000200034

[18] Zasadny MF, Bull RM. Assessing competence in undergraduate nursing students: the Amalgamated Students Assessment in Practice model. Nurse Educ Pract. 2015; 15(2): 126-33. PMid:25682194 http://dx.doi.org/10.1016/j.nepr.2015.01.003

[19] Mattson J, Forsner M, Bolander-Laksov K. Facilitation of learning in specialist nursing training in the PICU: the supervisors' concerns in the learning environment. Journal of Nursing Education and Practice. 2014; 4(12): 34-41. http://dx.doi.org/10.5430/jnep.v4n1 $2 \mathrm{p} 34$

[20] Kapborg I, Bertero C. Critiquing bachelor candidates' theses: are the criteria useful? Int Nurs Rev. 2002; 49(2): 122-8. PMid:12094829 http://dx.doi.org/10.1046/j.1466-7657.2002.00123.x

[21] Hart E, Bond M. Action research for health and social care: A guide to practice. Buckingham: Open University Press.

[22] SFS. Act on ethical review of research involving humans Stockholm: Ministry of Education. 2003. Available from: http://www.riksdagen.se/sv/dokument-lagar/dokument/ svensk-forfattningssamling/lag-2003460-om-etikpro vning-av-forskning-som_sfs-2003-460

[23] SFS. Personal Data Act. Stockholm: Ministry of Justice. 1998 Available from: http://www.riksdagen.se/sv/dokument-1 agar/dokument/svensk-forfattningssamling/lag-20034 60-om-etikprovning-av-forskning-som_sfs-2003-460

[24] Susman GI, Evered RD. An Assessment of the Scientific Merits of Action Research. Administrative Science Quarterly. 1987; 23(4): 582-603. http://dx.doi.org/10.2307/2392581

[25] O'Brien BB. Nursing Praxis: An exploration of changing nursing practice in the evolution of an embryonic nursing unit. Melbourne: Deakin University; 1991.

[26] Gill FJ, Leslie GD, Grech C, et al. Developing and Testing the Standard of Practice and Evaluation of Critical-Care-Nursing Tool (SPECT) for Critical Care Nursing Practice. J Contin Educ Nurs. 2014; 45(7): 312-20. PMid:24972098 http://dx.doi.org/10. 3928/00220124-20140620-02

[27] Gill FJ, Leslie GD, Grech C, et al. Health consumers' experiences in Australian critical care units: postgraduate nurse education implications. Nurs Crit Care. 2013; 18(2): 93-102. PMid:23419185 http://dx.doi.org/10.1111/j.1478-5153.2012.00543.x

[28] The CoBaTrICE collaboration. The views of patients and relatives of what makes a good intensivist: a European survey. Intensive Care Medicine. 2007; 33: 1913-1920. PMid:17701164 http://dx.doi.org/10.1007/s00134-007-0799-4 